\title{
Hormone therapy study restokes debate over breast cancer risk
}

\author{
n Cite as: CMAJ 2019 September 30;191:E1088-9. doi: 10.1503/cmaj.1095815
}

Posted on cmajnews.com on Sept. 10, 2019

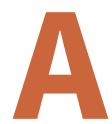
meta-analysis has linked menopausal hormone therapy to increased risk of breast cancer, but some experts argue that the study is flawed.

The paper, published in the Lancet, showed there was one additional case of breast cancer for every 50 average-weight women aged 50-69 in developed countries who took daily doses of estrogen and progesterone for five years. The risk increased the longer women took the therapy and persisted more than a decade after they stopped, twice as long as previously thought.

The findings have revived a longstanding debate over the safety of hormone replacement therapy (HRT), with some critics of the meta-analysis warning that it overstates the risks. The authors, however, say there are no easy answers and women must weigh the risks and benefits for themselves.

"We don't want to cause undue alarm and we don't want to cause undue reassurance," said coauthor Sir Richard Peto, a professor of medical statistics and epidemiology at the University of Oxford in England. "It's the job of doctors to help patients to get a feel for what's right for them."

Peto and coauthors conducted a metaanalysis of 58 studies, which included 143887 postmenopausal women with inva- sive breast cancer and 424972 who did not develop breast cancer. The risk of breast cancer was found to have increased the longer women used hormone therapy, doubling for women who used it for 10 years compared to five. However, there was no increased risk for women who used hormone therapy for less than a year, and those who used it intermittently were found to have lower risk than those who used it daily.

These findings support existing recommendations that women use hormone therapy for the shortest time and at the lowest dose that works for them, said Dr. Robert Langer, board member of the International Menopause Society. However, he and others warn, the meta-analysis isn't applicable to modern HRT regimens and overstates the risks, especially for younger women.

According to the International Menopause Society and the British Menopause Society, most of the data in the Lancet paper are from older observational studies of formulations and doses of hormone therapy that are no longer recommended.

Peto said using older data can't be avoided in a study of long-term effects. He's also skeptical that newer forms of HRT would be much different. "You have to give enough dose to have a pharmacological effect, and it's not clear that the effective suppression of symptoms can be disassociated from unwanted effects on breast cells."
A meta-analysis that shows breast cancer risk increases the longer women take hormone replacement therapy has revived longstanding debate over the safety of the treatment. 
The International Menopause Society also cautions that breast cancer risk reported for women who go through menopause before age 45 must be seen in context of the risk they would face if they still had their periods. Women who go through early menopause have a third lower risk of breast cancer to begin with, said Langer. Hormone replacement therapy restores their risk to what it would have been if they still had their periods, but also provides protective benefits against osteoporosis, cardiovascular disease and premature death. "They should not be scared away by a paper like this."

Langer acknowledged that the decision is more complicated for older women. But for those suffering from hot flashes that keep them up all night, or other disruptive symptoms of menopause, the relief HRT provides may be worth the added risk.
According to Peto, there are other ways to reduce the risk of cardiovascular disease and osteoporosis that don't carry added risk for breast cancer. He also questions the independence of organizations like International Menopause Society from pharmaceutical funding. "I think that they are selective in what they present as evidence."

Lauren Vogel, CMAJ 